\title{
Small aircraft as a means of transport in Spain
}

\section{Javier Romero*}

Aerospace, Transport and Security Department, Centre for the Development of Industrial Technology (CDTI),

Cid 1, 28001-Madrid, Spain

E-mail: jjrracdti.es

*Corresponding author

\section{Miguel Palacios}

Departamento de Ingeniería de Organización, Administración de Empresas y Estadística,

Escuela Técnica Superior de Ingenieros Industriales,

Universidad Politécnica de Madrid,

José Gutiérrez Abascal, 2, Madrid, Spain

E-mail: mipalacios@etsii.upm.es

\section{Javier Tafur}

Departamento de Ingeniería de Organización,

Administración de Empresas y Estadística,

Escuela Técnica Superior de Ingenieros Aeronáuticos,

Universidad Politécnica de Madrid,

Pza. de Cardenal Cisneros, 3, Madrid, Spain

E-mail: javier.tafur@upm.es

Abstract: Personal aviation represented 9\% of the aircraft movement in Europe in 2006, and it is expected to grow over the coming years. According to the European Personal Air Transportation System (EPATS) study, Spain, along with France and Italy, are the European countries with greater growth prospects.

The objective of this paper is to present research results focused on the potential growth of the personal aviation market in Spain and its regions. The research is mainly based on the secondary data of a survey (Movilia) from the Spanish Ministry of Public Works and Transport.

Keywords: small aircraft; transport; market; personal mobility; Spain.

Reference to this paper should be made as follows: Romero, J., Palacios, M. and Tafur, J. (2012) 'Small aircraft as a means of transport in Spain', Int. J. Aviation Management, Vol. 1, No. 3, pp.217-229.

Biographical notes: Javier Romero graduated in 1990 in Industrial Organisation at Universidad Politécnica de Madrid. His Master thesis deals with the business model in European airports. He currently works at the Aerospace, Transport and Security Department in a public entity, answering to the Spanish Ministry for Science and Innovation. 
Miguel Palacios is a Professor in Management at the Department of Industrial Management and Business Administration at ETS Ingenieros Industriales (Universidad Politécnica de Madrid). He is also affiliated at the 'Asociación para el Desarrollo de la Ingeniería de Organización (ADINGOR)' and some other research groups at UPM. He received his $\mathrm{PhD}$ in 2005 from UPM University and his MBA in 1999 from MIT Sloan School of Management. His main research interests lie in the field of new business models and innovation strategies.

Javier Tafur is a Professor at the Department of Industrial Management and Business Administration at ETS Ingenieros Aeronáuticos (Universidad Politécnica de Madrid). He is also affiliated at the 'Asociación para el Desarrollo de la Ingeniería de Organización (ADINGOR)' and some other research groups at UPM. He received his PhD in 2005 from UPM University and his MBA in 1998 from IE Business School. His main research interests lie in the field of new business models and innovation strategies.

This paper is a revised and expanded version of a paper entitled 'Small aircraft as a personal mean of transport' presented at 2010 World Conference of Air Transport Research Society in Porto, Portugal, 6-9 July 2010.

\section{Introduction}

Transport is a sector that contributes much to the economic, social and environmental needs of society. The mobility of goods and people is an essential component of the competitiveness of industry and services, and it is also a fundamental right of the citizens (Commission of the European Communities, 2008).

In this context, personal air transport is beginning to arise as an alternative form of transportation. In this context, there are two initiatives, the European Personal Air Transportation System (EPATS) and, in the USA, the Small Aircraft Transportation System (SATS), with the objective of developing a new transportation system based on newly-designed small and smart aircraft, which are mostly for personal use (Rohacs, 2010).

The SATS fleet structure includes 4-7-seat piston and jet aircraft operating at both small and large airports. The EPATS aircraft structure includes 4-7-seat piston and turbo aircraft, offering mainly air taxi and on-demand service, and 9-19-seat turbo commuters, offering low-flow, interregional scheduled transport and operating at small regional and local airports (EPATS, 2007).

Combining the two initiatives, small aircraft provide 4 to 19 seats for personal air transport, business aviation, or air taxis for more flexible and comfortable transport. Currently, general aviation represents $9 \%$ of the movement of aircraft in Europe (Commission of the European Communities, 2008), and demand for such transportation is expected to grow over the coming years, according to data on air traffic trends and aircraft orders.

This mode of transportation will be an elective with respect to other modes (car, train, and traditional air transport). However, estimates show that passengers travelling on personal aircraft would likely be those who typically use road and traditional air transport modes (Laplace, 2008). 
The main purpose of this paper is to present research results focused on the possible use of small aircraft as an alternative to other transportation modes in Spanish society. The research is presented in the following phases:

1 literature review describing the search and analysis of articles published in scientific journals dealing with factors that affect utilisation of small aircraft, general aviation, and other modes of transport

2 data collection consisting of the examination of documents and official data related to transport in Europe and Spain

3 analysis and assessment of data collected.

To achieve its objectives, the paper is organised as follows. First, it provides some information about European transport, particularly with regard to Spain. Then it presents the small aircraft as a mode of transport. The next section provides an analysis of the use of personal aviation in Spain. Finally, Section 5 provides a conclusion.

\section{The European transport and the different modes}

The transport sector generates $7 \%$ of the GDP and nearly $5 \%$ of the jobs in the European Union. To ensure the prosperity of Europe, it is essential to have effective transport systems with the following characteristics (Commission of the European Communities, 2006):

- high level of personal mobility, private and business, in the whole Union

- environmental protection

- innovation in support of the previously mentioned objectives

- international connectivity that reinforces sustainable mobility, environmental protection, and innovation.

The evolution of European transport has brought the following results (Commission of the European Communities, 2008):

- a continental dimension as a consequence of the enlargement of the EU

- consolidation at the European level, especially in sea and air transport

- rapidly changing technology through research and innovation

- changes in the international context and economic globalisation, affecting trade flows and causing the demand for international transport to and from the emerging economies to increase

- an already largely established basic legal framework for the internal market.

In Europe, transport has been characterised by the predominance of the car, with uninterrupted growth in its use since 1995 (see Figure 1). This use represents $85 \%$ of the passengers. The same trend has occurred in air transport, being one of the modes with the greatest increase in recent years. With regard to the European internal market, air transport has become an industrial reality and an engine of growth. Restructuring and 
integration of this mode are quite advanced, and the market has expanded with the multiplication of routes that provide service in Europe, the entry of low cost airlines, and the development of regional airports (EUROSTAT, 2009).

Figure 1 Passenger transport in Europe EU27 (billion passengers-km.)

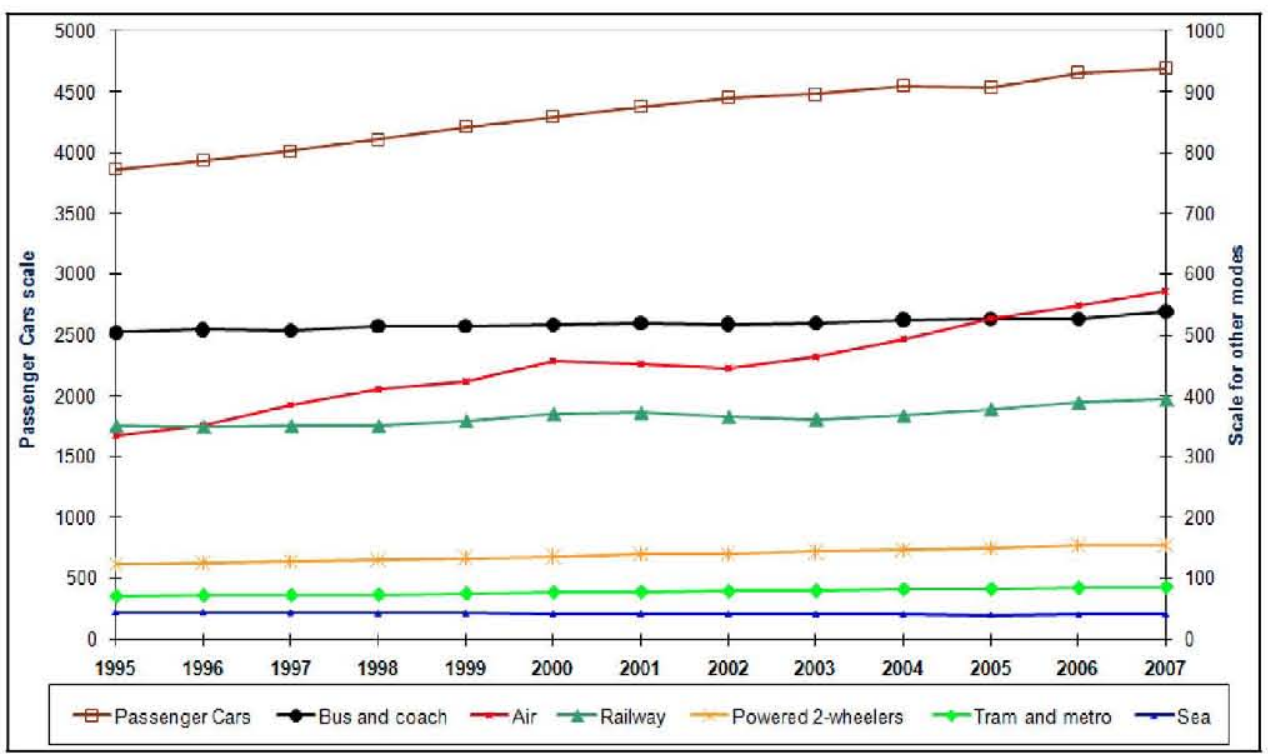

Source: European Commission

Figure 2 National flights passengers in GE, FR, IT, UK and SP

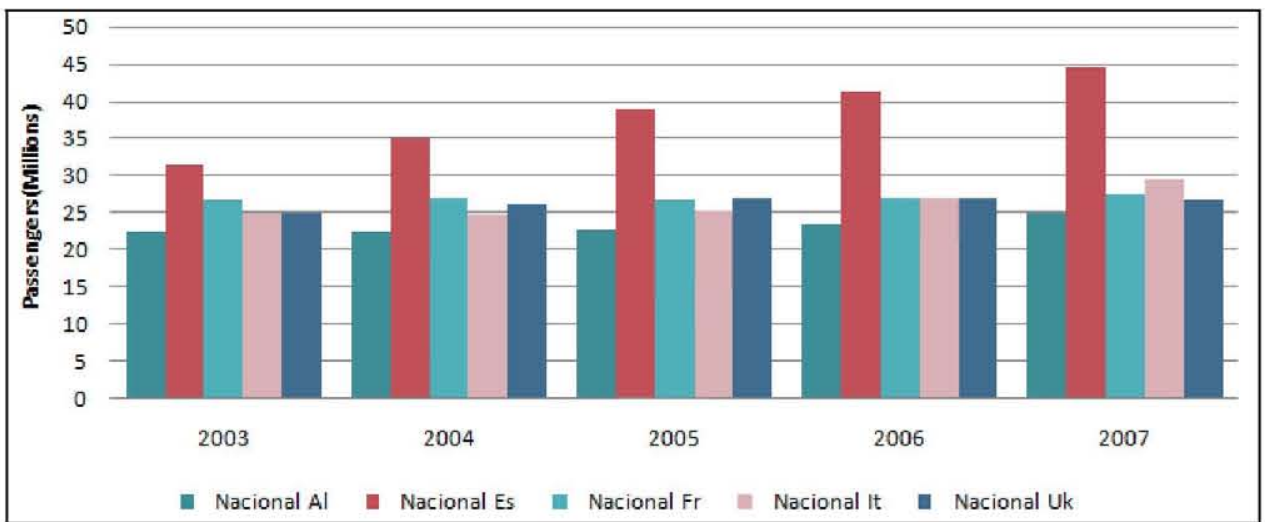

Source: EUROSTAT

After analysing a more global context and noting the influence of auto and air modes, this study compares travel in Spain with that in similar countries, such as Germany, the UK, France and Italy. In relation to the flights, the volume of passengers in Spain is greater than that in the other countries, which could be motivated by tourism, which encourages the use of aircraft travel (see Figure 2). 
The use of the car in Spain is similar to that in other countries, but the tendency to use commercial aviation at the national level is higher than it is in the other countries (see Figures 2 and 3 ).

Figure 3 Car passengers in GE, FR, IT, UK and SP

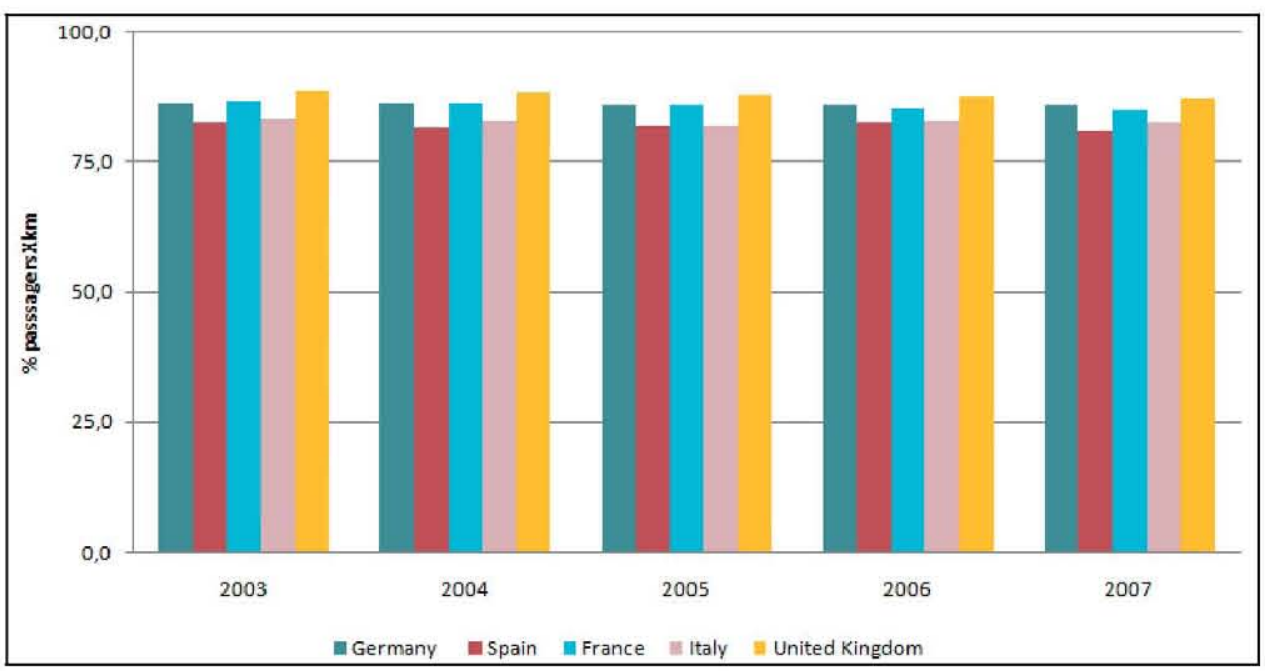

Source: EUROSTAT

In conclusion, transport in Spain is dominated by the car, although aircraft travel is becoming more popular than in other European countries. Furthermore, the enlargement of the European Union gives aircraft transportation a continental dimension, and advances in technology make it one of the strategic sectors with a greater future.

\section{Small aircrafts as a means of transport}

A critical feature of the modern world is the mobility of people and goods, and all means of transport have contributed to making the world smaller. Air transport represents the main mode associated with this trend. Furthermore, during the twentieth century, it has surpassed some modes of transport. The choice of a mode of transport depends mainly on the trip distance and the access to facilities within a certain distance (Scheiner, 2010; Trani et al., 2006; Wittmer and Laesser, 2009). In this regard, the use of the car is greatest in local situations, whereas air transport dominates over long distances (L'Hostis, 2009).

In this context, personal mobility is characterised by self-propelled movements that can range from a walk to movements requiring the use of different types of technologies, such as the bicycle, car and aircraft. An emerging means of transportation is personal air transport, whose use is related to the demand of more flexible transport. The most influential factors determining the choice of a mode of transport are the following (Commission of the European Communities, 2008):

- need for greater mobility, flexibility and point-to-point service

- congestion in major airports 
- protection and security needs

- need to increase productivity in companies, requiring their executives to travel more efficiently

- development of new technologies that improve the efficiency and costs of aircraft.

Traditionally, the use of small aircraft has been limited to aviation enthusiasts. Such aircraft are known to be expensive, noisy, uncomfortable, difficult to operate and unsafe (Moore, 2003). Widespread access will occur when such aircraft become secure and easy to use and maintain. The use of small aircraft can provide substantial time savings and improve quality of life. Moreover, it can provide strong benefits for regional economies. Therefore, these regions should invest in airport facilities to position themselves for future urban growth (Johansson, 2007).

In Europe, about 2000 smaller airports (see Figure 4) exist with varying levels and quality of infrastructure. These smaller airports will grow and create new markets around the airports, which will favour the local economy. Specifically, restaurants, hotels and taxi services will gain many new customers (EPATS, 2008).

Figure 4 All airports and landing fields in Europe

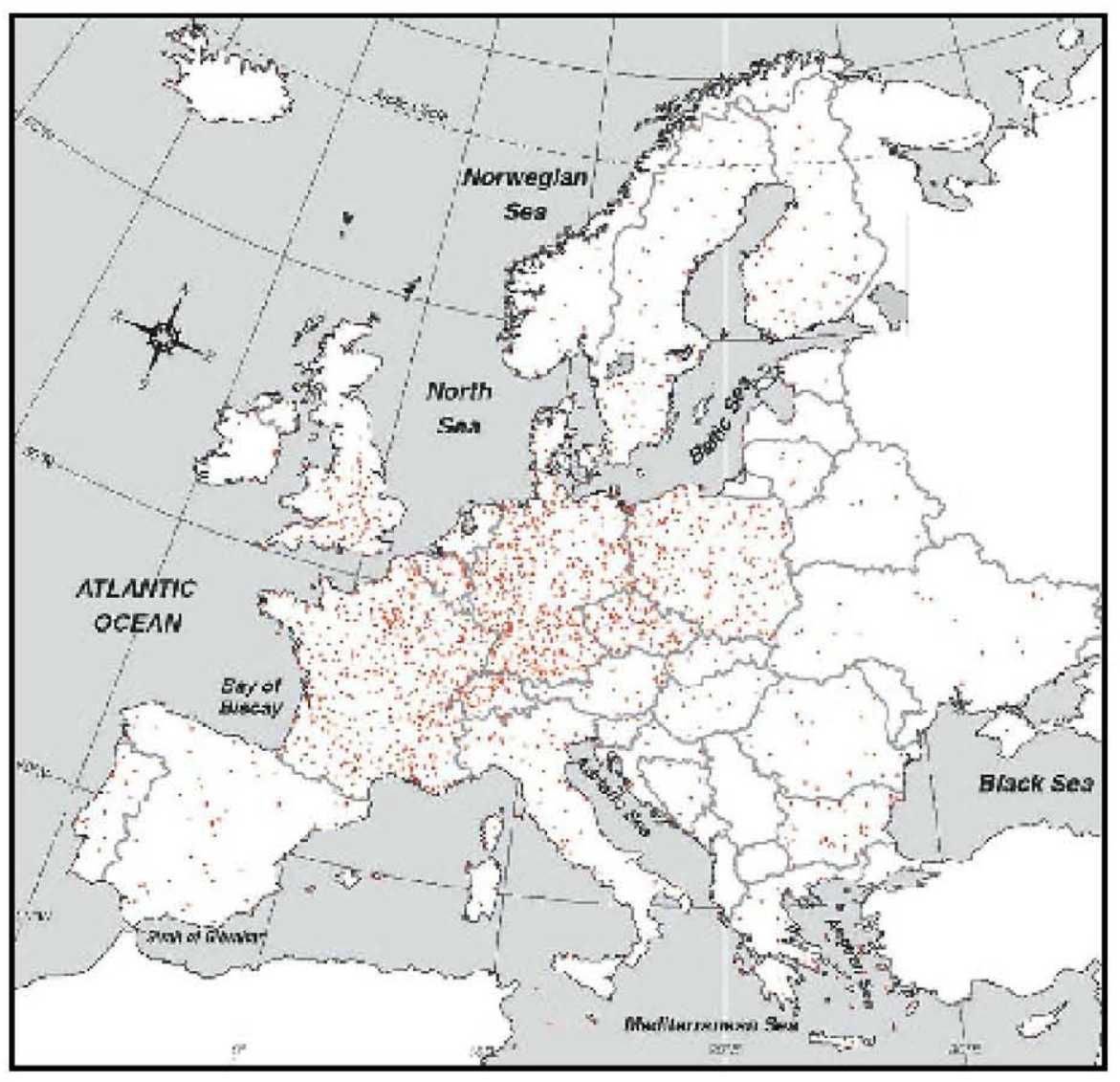

Source: EPATS 
Small aircraft is an alternative to the car with respect to the economic value of travel time reduction, especially for business purposes (McGrath and Young, 2002). The reduction in time between origin and destination has been the main factor for the selection to the automobile. Today, one of the services that is rising in this area is the air taxi, especially for businessmen or rich people.

In the rural and regional areas of the USA, there is a need for interurban transport to cities less than 500 kilometres away. The trend in this situation is to use the car rather than another mode of transport because of the lack of infrastructure. Personal aircraft provides mobility, capacity and quality of life that can generate demand. However, door-to-door transportation has a very large potential up to distances of 400 kilometres (Moore, 2003). Today, an aircraft is much more expensive than a car, but this difference is decreasing.

An important transportation requirement in the USA is that airports increase their capacity to absorb the large number of operations generated by small aircraft, which may triple within the next 15 to 20 years (Baxley et al., 2008). This increase would saturate their 35 major airports in the USA, and the local infrastructures could benefit because they are closer to private houses.

With regard to the EU, major airport capacity is very limited, and new construction is complex. When the travel distance reaches 400 kilometres, other transportation modes, such as the high-speed train, create competition. One option to consider is the helicopter, which can compete with conventional aircraft and high-speed trains between medium and long distances, i.e., between 400 and 800 kilometres (Correnti et al., 2007). Nowadays, the use of helicopters is limited to a certain purchasing level. This limitation constitutes an opportunity for personal aircraft, which can always be utilised when necessary infrastructures exist.

Figure 5 Potential personal aviation traffic in 2020 (millions PKM)

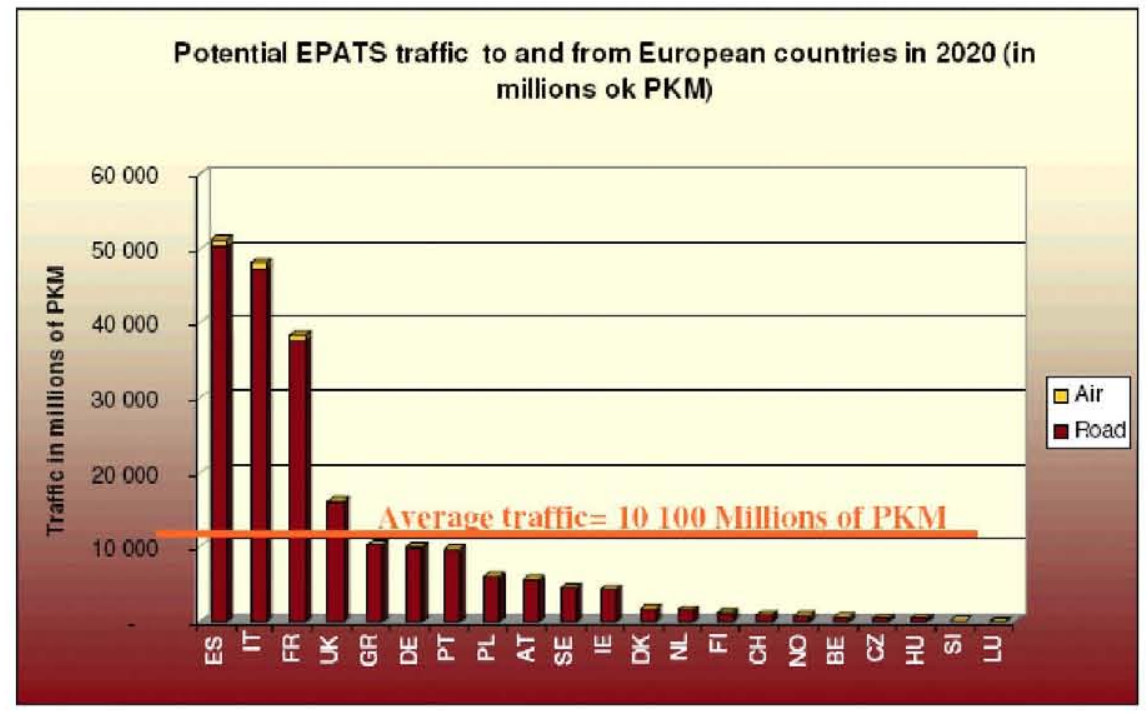

Source: EPATS, ESPON, ASSES 
In the European region (see Figure 5), leisure travellers are unlikely to choose personal aviation (both from the road and air transport mode). Transferred traffic would only pertain to business passengers. In 2020, this transfer of traffic would represent 152 billion passenger-kilometre or 319 million passengers, and $99 \%$ of this traffic would derive from those who typically use road transport (Laplace, 2008).

Finally, the literature review shows that personal aviation as a means of transport could be utilised as an alternative to the car and the airliner. Furthermore, independent of the transport cost, the use of small aircraft depends on such factors as those represented in Figure 6. Factors related to the size of airports and aerodromes, as well as legislation and normative practices, are not treated in the current study.

Figure 6 Factors influencing the use of personal aircraft

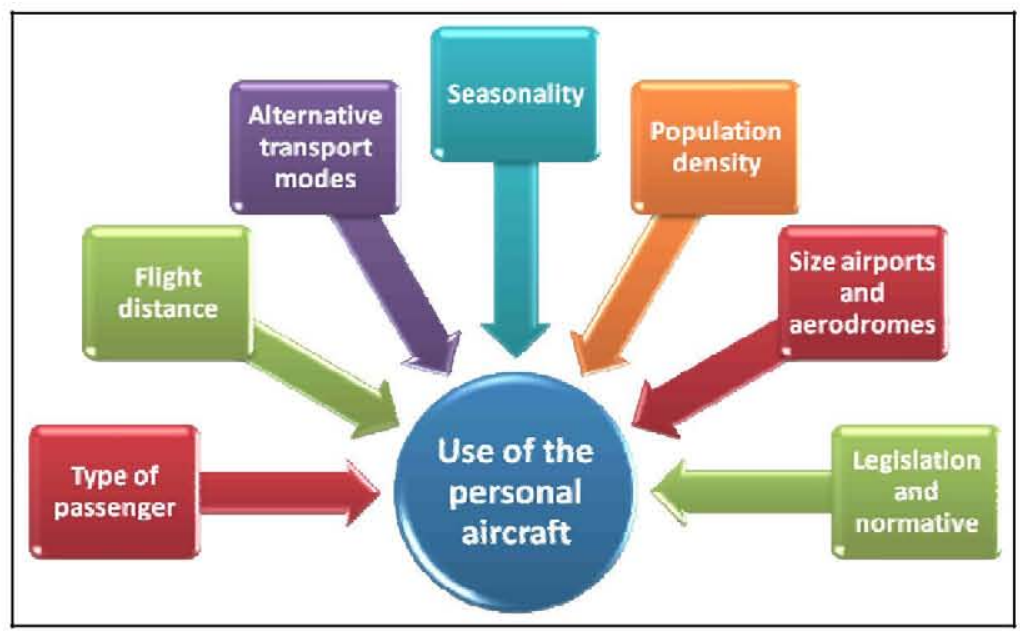

\section{Personal aviation in Spain}

Personal aviation in Spain is lower than in its neighbouring countries, mainly due to the lack of infrastructure (see Figure 4). However, Spain presents an ideal climate for its development. It has considerable distances between its important urban centres, which can lead to growth in line with that of other European countries (MITYC/CDTI, 2008). Furthermore, investment in tourism infrastructure and the decentralisation of economic and social activities in peripheral areas, in particular, the islands (Tsekeris, 2009), would greatly aid the growth of personal aviation.

The transferred traffic to personal aviation would represent 43 million flights in Europe, with Italy, Spain and France being the European countries with the highest levels of traffic. The predominance of Spain and Italy can be mainly explained by the high level of domestic traffic in these countries, which represents more than $50 \%$ of the total traffic to and from these countries (Laplace, 2008).

The research presented in this paper is based on the study of the use of different modes of transport in Spain, from which personal aircraft could capture a market share, mainly from airline and car travellers (Laplace, 2008), in distances up to 1,000 kilometres, the range to which personal aircraft are most suited. 
In relation to Spain, this study uses data from the survey of the mobility of the people resident in Spain (Spanish Ministry of Public Works and transport) for the years 2001 and 2007, which aims to obtain sufficient information to enable the understanding of mobility pattern characteristics and their determinants. Mobility inquiry is organised into two distinct phases. The first phase primarily addresses the characteristics of 'everyday' mobility. The second phase primarily examines longdistance mobility and mobility involving overnight stays in a location other than the residence.

The car is the dominant mode of transport in Spain, whereas aircraft affords more incremental use (see Figure 7).

Figure 7 Travel in the different modes of transport in Spain

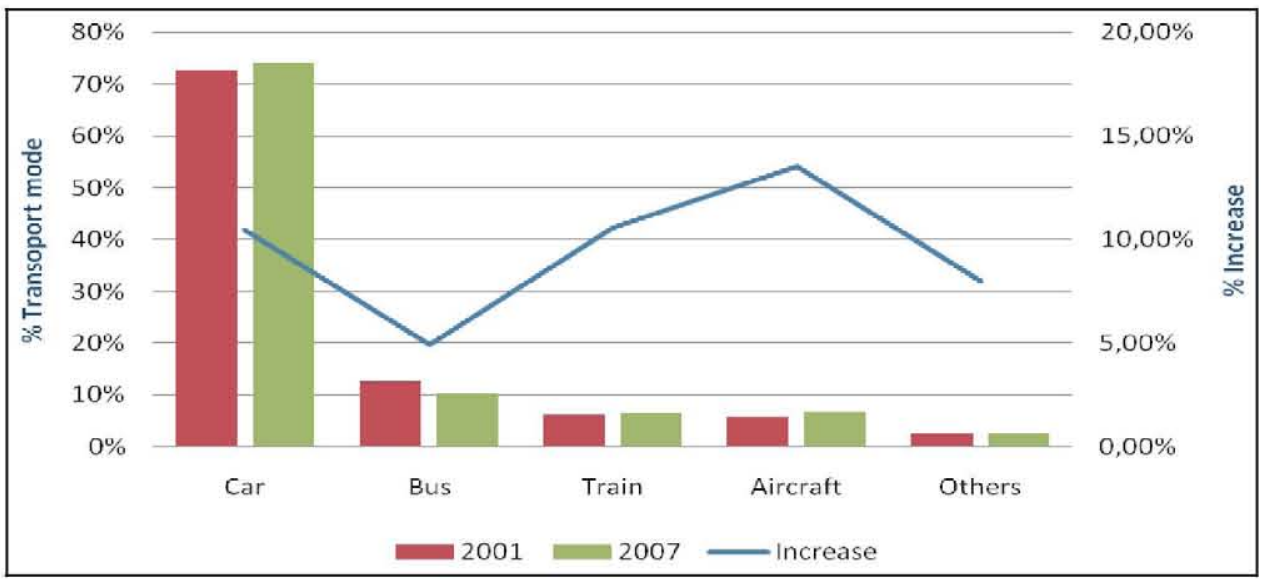

Source: Movilia - Spanish Ministry of Public Works and Transport

Figure 8 Seasonality of the use of the car in Spain

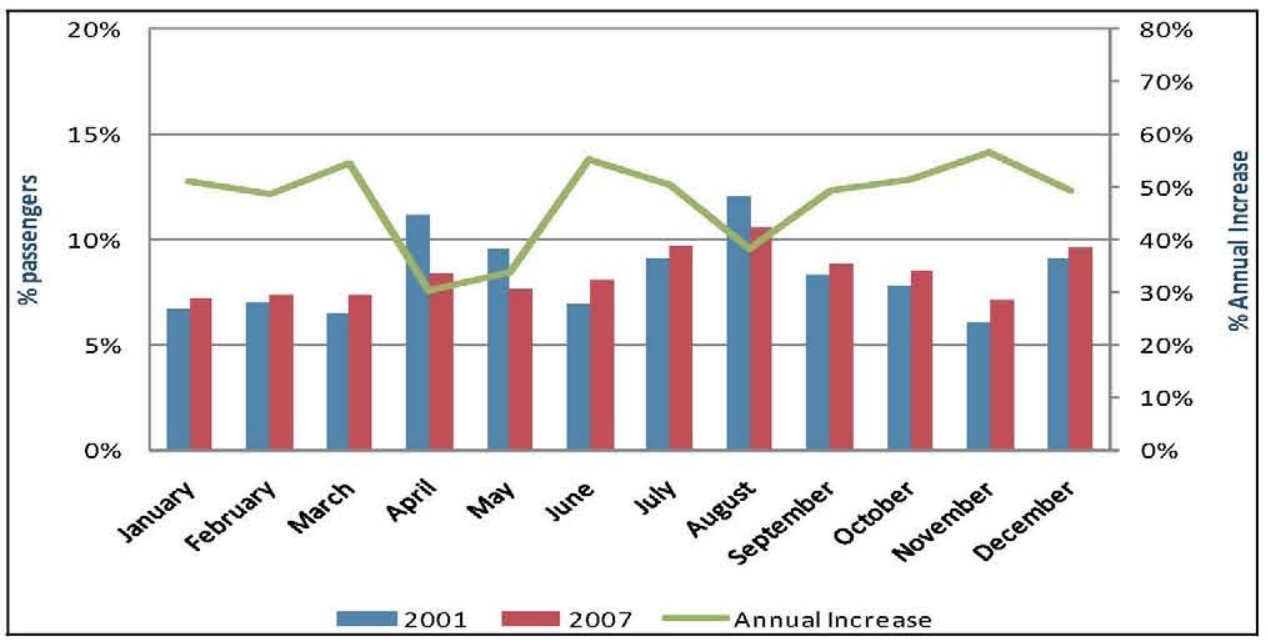

Source: Movilia - Spanish Ministry of Public Works and Transport 
Figure 9 Seasonality of the flights in Spain

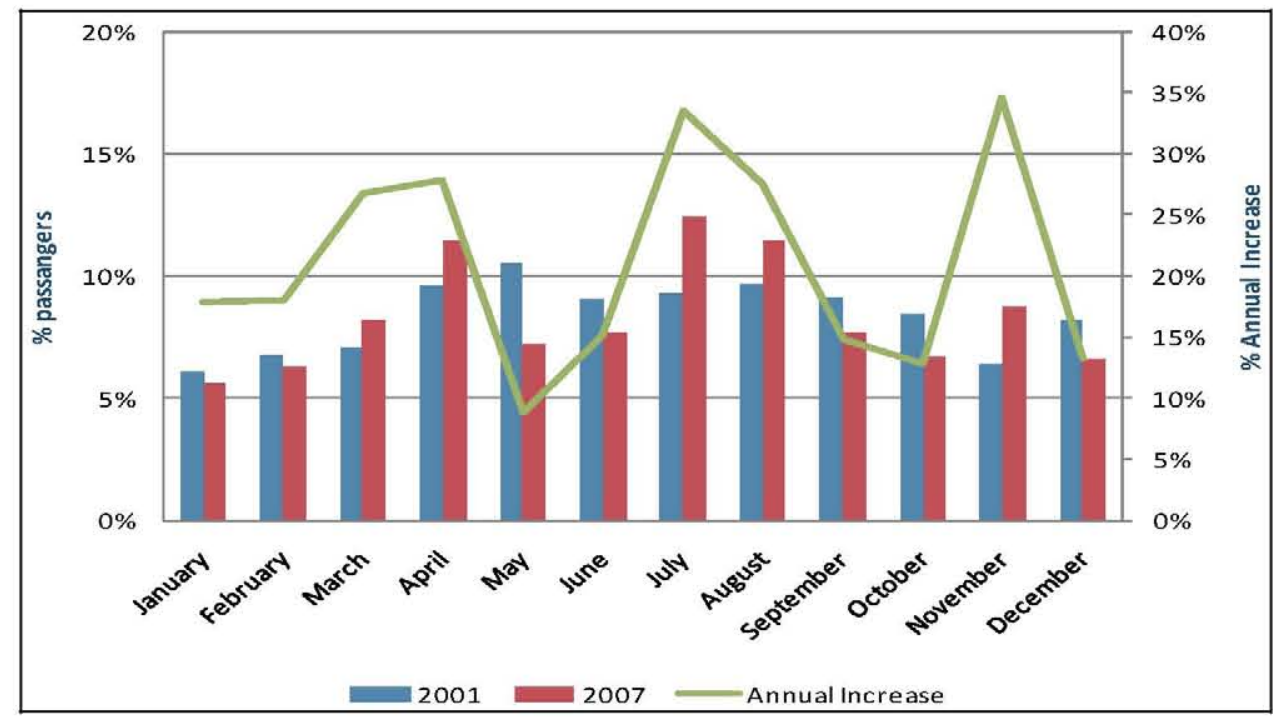

Source: Movilia - Spanish Ministry of Public Works and Transport

Once compared, these different modes of transport are evaluated over the year. It should be observed that these evaluation periods do not match the periods of the year in which most of these modes of transport have increased. In the case of car, usage increases correspond to March, June and November, whereas in the case of the plane, the growth periods are April, July, August and November. The car shows decreased utilisation in April, May and August, while aircraft use considerably decreases in May, June, September, October and December. Both modes of transport in Spain have some complementarity along the year (see Figures 8 and 9).

Figure 10 Travel in cars and aircraft in Spanish regions

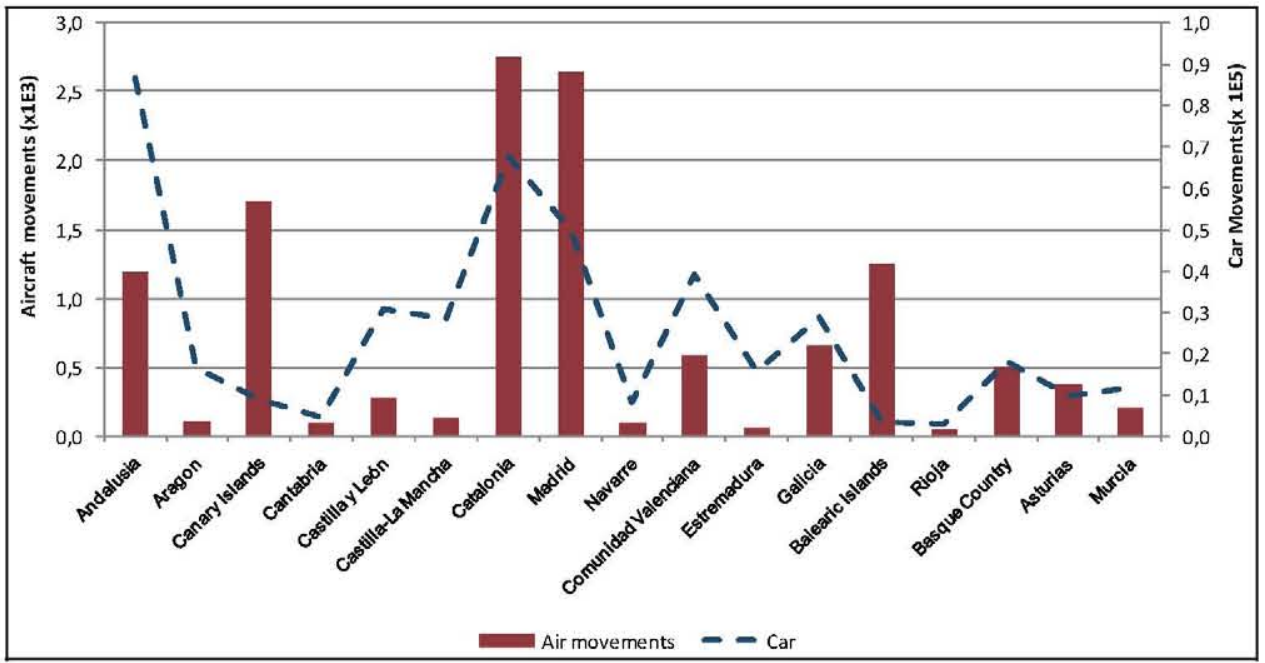

Source: Movilia - Spanish Ministry of Public Works and Transport 
Important to this analysis is the potential demand in the different regions in Spain (see Figure 10). In this respect, Spain could be divided in three regions:

- Regions with the largest car and aircraft movements, primarily located in the Iberian Peninsula (Madrid, Catalonia and Andalusia).

- Islands with high volume of aircraft movements, which are the Canary Islands and the Balearic Islands.

- Remaining regions. Two of these regions (Basque Country and Valencia) have a population density (see Figure 11) higher than that of the rest of this group, and it is expected that these regions will show more use of personal transport.

These circumstances pose challenges for managers trying to promoting access to this new market of small- and medium-sized enterprises as well as for countries with little history in aeronautics. As a result, it will be up to new entrepreneurs, who perceive a market with great potential, to capitalise on the opportunities presented by modes of transport such as the car or commercial aircraft.

Figure 11 Main metropolitan areas in Spain

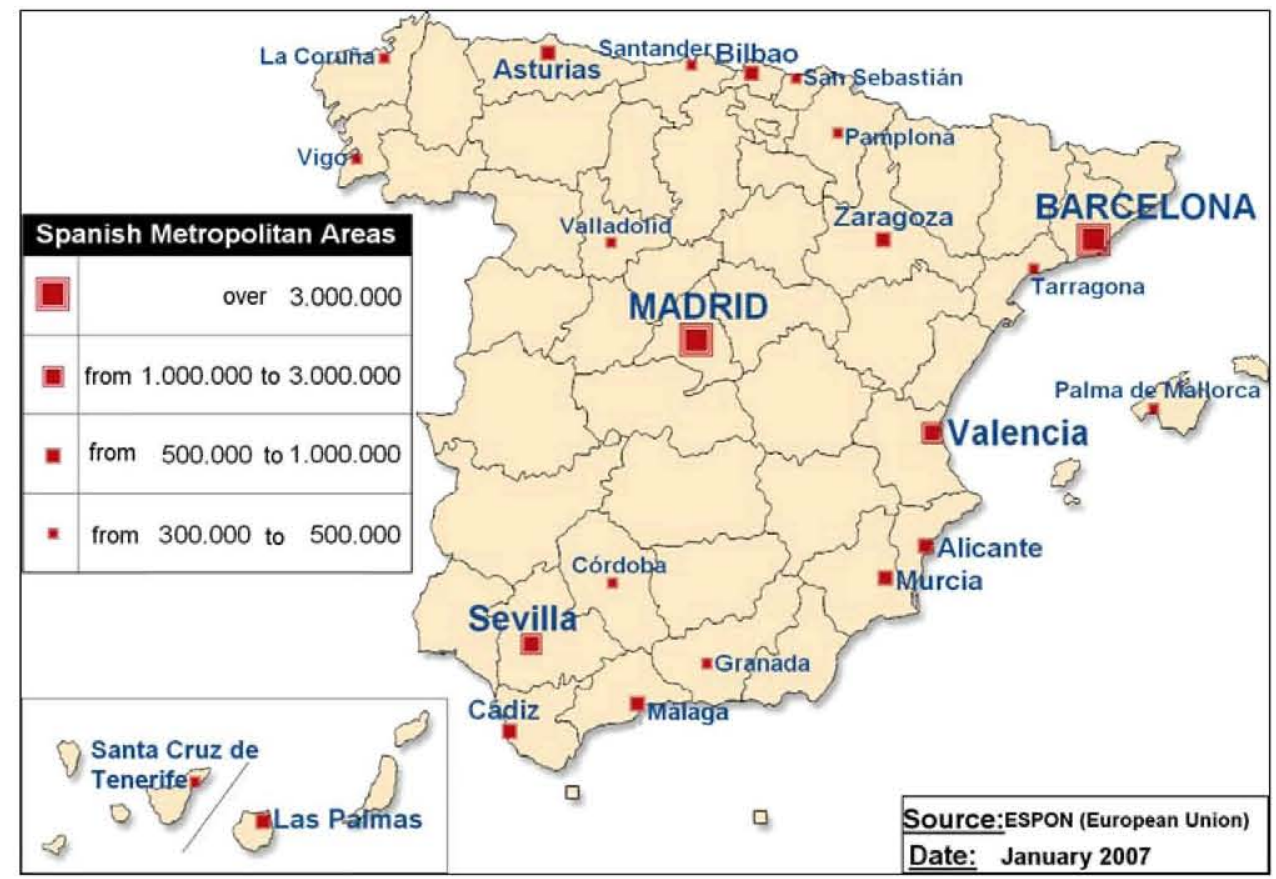

Source: ESPON (2007)

Finally, the potential impact of the current financial crisis is of great importance because it can affect the country's economic growth and, as a result, the possible growth of air transport that is expected to recover significantly with the economy, as it has in the past (Marazzo et al., 2010).

The main results of the research are the following: 
- The main modes that will transfer traffic to personal aviation will be the car and traditional airline transport, in line with the literature review.

- The main mode of transport in Spain is the car, as in other European countries.

- Between 2003 and 2007 air transport is the mode with the largest increase in Spain.

- The months with the most car use in Spain are April, May, July and August. The timing is different for air transport movements. There are differences throughout the year. These months correspond with holidays in Spain, so changes in mode of transport would not come only from business travels. This result is different from that obtained in the EPATS project.

- There are three types of regions in Spain from the point of view of car movements and aircraft movements (sources of the possible demand for small aircrafts). In the context of population density, there are regions of Spain (Basque Country and Valencia) with a high possibility of transferring traffic to personal aviation.

It can be concluded that there is a tendency to use individual transportation, automotive resources, and air transportation at distances up to 1,000 kilometres. It could be inferred that, as in other developed countries, the demand for small aircraft travel could increase in Spain and represent a real alternative in the coming years, even more if regulation would be necessary to adapt and allow for building the infrastructure needed. These needs will be studied in the context of the European Research programme, Single European Sky ATM Research Programme (SESAR) (EPATS, 2007).

\section{Conclusions}

In Europe, transport has taken on a continental perspective, and air transport represents a strategic resource for Europe's competitiveness. The mobility of human beings, particularly through personal transport, will be increasingly critical in the future. Small aircraft will play a rapidly increasingly role in this context. However, this new market will pose challenges to small and medium-sized enterprises and also to countries with little history in aeronautics.

In this framework, utilisation of small aircraft by the general public is dependent on the development of new models that are more accessible and easy to use and maintain. There is also a need to create new infrastructures because current capacity could be saturated by the large number of potential operations.

In Spain, the use of the car and greater aircraft preference indicates the growth potential of personal aviation (small aircrafts), both private and business, which is expected to be more affordable, as it was in the case of the car.

Finally, our conclusions are conditioned by the limitation on the information available from the survey Movilia (Spanish Ministry of Public Works and Transport) because it only produces two years of data (2001 and 2007). Future research could contrast the results for Spain with those of other countries and regions in the world. 


\section{References}

Baxley, B.T., Williams, D., Consiglio, M., Adams, C. and Abbott, T. (2008) 'Small aircraft transportation system, higher volume operations concept and research summary', Journal of Aircraft, Vol. 45, No. 6, pp.1825-1834.

Commission of the European Communities (2006) 'Keep Europe moving - sustainable mobility for our continent', Mid-term review of the European Commission's 2001 Transport White Paper.

Commission of the European Communities (2008) 'Communication from the commission - an agenda for sustainable future in general and business aviation'COM/2007/0869 final.

Correnti, V., Caprì, S., Ignaccolo, M. and Inturri, G. (2007) 'The potential of rotorcraft for intercity passenger transport', Journal of Air Transport Management, Vol. 13, No. 2, pp.53-60.

EPATS (2007) Small Aircraft Requirements \& Potential Demand.

EPATS (2008) EPATS Airports General Requirements.

ESPON (2007) European Spatial Planning Observation Network, available at http://www.espon.eu/.

EUROSTAT (2009) Panorama of Transport 2009.

Johansson, O. (2007) 'Inter-urban competition and air transport in the deregulated era: the Nashville case', Journal of Transport Geography, Vol. 15, No. 5, pp.368-379.

L'Hostis, A. (2009) 'The shrivelled USA: representing time-space in the context of metropolitanization and the development of high-speed transport', Journal of Transport Geography, Vol. 17, No. 6, pp.433-439.

Laplace, I. (2008) 'The demand for personal air transport in Europe', ILA Conference, Berlin.

Marazzo, M., Scherre, R. and Fernandes, E. (2010) 'Air transport demand and economic growth in Brazil: a time series analysis', Transportation Research Part E: Logistics and Transportation Review, Vol. 46, No. 2, pp.261-269.

McGrath, R.N. and Young, S.B. (2002) 'NASA's small aircraft costs versus automobile costs and the economic value of traveler time', Technovation, Vol. 22, No. 5, pp.325-336.

MITYC/CDTI (2008) Plan Estrategico Aviacion General, MITYC/CDTI.

Moore, M.D. (2003) 'Personal air vehicles: a rural/regional and intra-urban on-demand transportation system', Journal of the American Institute of Aeronautics and Astronautics (ALAA).

Rohacs, D.J. (2010) 'Evaluation of the air transport efficiency definitions and their impact on the European Personal Air Transportation System development', 14pp, Instytutu Lotnictwa.

Scheiner, J. (2010) 'Interrelations between travel mode choice and trip distance: trends in Germany 1976-2002', Journal of Transport Geography, Vol. 18, No. 1, pp.75-84.

Trani, A., Baik, H., Hinze, N., Ashiabor, S., Viken, J. and Dollyhigh, S. (2006) 'Nationwide impacts of very light jet traffic in the future: next generation air transportation system (NGATS)', AIAA Paper 2006-7763, September 2006.

Tsekeris, T. (2009) 'Dynamic analysis of air travel demand in competitive island markets', Joumal of Air Transport Management, Vol. 15, No. 6, pp.267-273.

Wittmer, A. and Laesser, C. (2009) 'Customer issues related to limited air connectivity', Journal of Air Transport Management, Vol. 15, No. 1, pp.23-25. 